\title{
SCIDiC
}

International Journal of Clinical Dermatology \& Research (IJCDR)

ISSN: 2332-2977

\section{Dermatologic Manifestation Of COVID-19: Review Of Case Series}

Review Article

Annisa Alviariza ${ }^{1 *}$, Luh Made Budiani ${ }^{2}$

${ }^{1}$ Internship Doctor, Dermato-Venereology Departement, Sanjiwani Gianyar Regional Hospital, Bali.

${ }^{2}$ Dermato-Venereology Departement, Sanjiwani Gianyar Regional Hospital, Bali.

Abstract

Background: SARS-CoV-2 infections, causing disease known as COVID-19, has been associated with a myriad of symptoms, including dermatological ones. Despite there has been a consensus on pulmonary and systemic signs and symptoms of COVID-19, the same cannot be said of dermatological ones. We write in attempt to find a common theme of dermatological manifestations of COVID-19.

Methods: We conducted literature searches from Medline databases as well as Google Scholar using keywords "cutaneous manifestations of COVID-19" and "dermatologic manifestations of COVID-19". We included case series in our pooled descriptive analysis to describe types of cutaneous eruptions, localizations, and associated symptoms among COVID-19 patients with confirmed RT-PCR results.

Results: We included 12 case series in our pooled analyses with 2 more analyzed separately due to non-comparable data presentations. The results identified common types of cutaneous eruptions associated with COVID-19 to be maculopapular rash, urticaria, vesicular rash, vascular rash. Eruptions tend to be localized on the trunks, with lesser frequency found on extremities, and eruptions are often accompanied by pruritus of varying intensity. These various eruptions are associated with two distinct pathological pathways, namely inflammation of skin tissues, causing inflammatory rashes, and hypercoagulable state which is associated with vascular rashes.

Conclusion: Our literature review identified several common types of cutaneous eruptions associated with COVID-19 with different proposed pathophysiological mechanisms for inflammatory and vascular rashes. This review is limited by its data sources which includes only case series as well as the fact that at this stage in the pandemic, little biomolecular research has been conducted to definitively associate SARS-CoV-2 infection with cutaneous manifestations.

Keywords: COVID-19; SARS-CoV-2; Dermatologic Manifestations; Cutaneous Eruptions.

\section{Introduction}

Since early 2020 the world is faced with a novel viral pandemic. SARS-CoV-2, a novel coronavirus strain related to previous novel coronaviruses such as SARS and MERS, is currently infecting most of the world. As of the writing of this article, there has been 14.3 million confirmed cases of coronavirus disease of 2019 (COVID-19), disease caused by SARS-CoV-2 infection, with 600 thousand deaths [1].

Dermatologic manifestation of primarily non-dermatologic viral infection has been previously described. As an example, hepatitis $\mathrm{C}$, a virus that primarily infect the liver, has been known to manifest as pruritus, palmar erythema, and lichen planus [2]. However, previous coronavirus diseases, namely SARS and MERS, has no had widely reported cutaneous manifestation [3].

Nevertheless, there has been reported cutaneous manifestations of COVID-19. A case series by Recalcati [4] in a letter to editor was among the first that describe a cutaneous manifestation of COVID-19. In that particular study, the manifestations include erythematous rash, urticaria, and vesicles with varying frequency.

\section{*Corresponding Author}

Annisa Alviariza,

Departement of Dermato-Venereology, Sanjiwani General Hospital Gianyar, Bali, Indonesia.

Tel: +6285212130127

Email Id: annisaalviariza@gmail.com

Received: April 14, 2021

Accepted: May 07, 202

Published: May 19, 2021

Citation: Annisa Alviariza, Luh Made Budiani. Dermatologic Manifestation Of COVID-19: Review Of Case Series. Int J Clin Dermatol Res. 2021;09(02):269-274. doi: http://dx.doi.org/10.19070/2332-2977-2100060

Copyright: Annisa Alviariza ${ }^{\circ}$ 2021. This is an open-access article distributed under the terms of the Creative Commons Attribution License, which permits unrestricted use, distribution and reproduction in any medium, provided the original author and source are credited. 
Since that first case series, further studies have reported similar manifestation, and other form of cutaneous manifestations, in COVD-19 patients around the world.

Cutaneous manifestation of COVID-19 remains an understudied and under-reported phenomenon. Nevertheless, dermatologists worldwide has reported more findings of cutaneous manifestation of COVID-19. This review attempted to summarize and interpret what is currently known of the phenomenon.

\section{Methods}

We conducted literature review to describe types of cutaneous lesions and efflorescence associated with SARS-CoV-2 infection. For that objective, we conducted systematic search of literature in open public scientific databases including Medline and Google
Scholar. Keywords used include "cutaneous manifestation of COVID-19" and "dermatologic manifestations of COVID-19". We include only case series studies and exclude all other study type. We conducted reference mining from all identified articles to find further articles that fulfill inclusion criteria. In the end, we selected for case series with comparable reported data which include patients with confirmed SARS-CoV-2 infection by RT-PCR, description of efflorescence, localization, symptoms, and onset.

From included studies we mined data on number of patients with SARS-CoV-2 infection, as confirmed from RT-PCR. Data mined including number of patients, type of cutaneous lesions found, and other characteristics. Based on these mined data, we conducted pooled analyses of these studies. We review the data and interpret it based on other relevant evidences.

Table 1. Characteristics of included studies.

\begin{tabular}{|c|c|c|c|}
\hline Reference & Region/Country & Number of Cases & Ref. No. \\
\hline Sachdeva et al, 2020 & Italy & 3 & 5 \\
\hline Gianotti et al, 2020 & Italy & 3 & 6 \\
\hline Recalcati et al, 2020 & Italy & 18 & 4 \\
\hline Dalal et al, 2020 & India & 13 & 7 \\
\hline Potekaev et al, 2020 & Russia & 15 & 8 \\
\hline Tammaro et al, 2020 & Italy & 2 & 9 \\
\hline Bouaziz et al, 2020 & France & 14 & 10 \\
\hline Landa et al, 2020 & Spain & 3 & 11 \\
\hline Alramthan dan Aldaraji, 2020 & Kuwait & 2 & 12 \\
\hline Marzano et al, 2020 & Italy & 22 & 13 \\
\hline Diotallevi et al, 2020 & Italy & 3 & 14 \\
\hline De Giorgi et al, 2020 & Italy & 53 & 15 \\
\hline Freeman et al, 2020a & United States & 23 & 16 \\
\hline Freeman et al, 2020b & United States & 171 & 17 \\
\hline
\end{tabular}

Table 2. Types of cutaneous manifestations of COVID-19.

\begin{tabular}{|c|c|c|c|c|c|c|}
\hline Reference & $\begin{array}{l}\text { Number } \\
\text { of Cases }\end{array}$ & $\begin{array}{c}\text { Maculopapule/ } \\
\text { Morbiliform }\end{array}$ & $\begin{array}{c}\text { Vesicle/pustule/ } \\
\text { bullae }\end{array}$ & Urticaria & Papulosquama & Vascular \\
\hline Sachdeva et al, 2020 & 3 & 2 & 1 & 0 & 0 & 0 \\
\hline Gianotti et al, 2020 & 3 & 3 & 0 & 0 & 0 & 0 \\
\hline Recalcati et al, 2020 & 18 & 14 & 1 & 3 & 0 & 0 \\
\hline Dalal et al, 2020 & 13 & 3 & 0 & 2 & 0 & 0 \\
\hline Potekaev et al, 2020 & 15 & 9 & 3 & 1 & 3 & 3 \\
\hline Tammaro et al, 2020 & 2 & 2 & 2 & 0 & 0 & 0 \\
\hline Bouaziz et al, 2020 & 14 & 4 & 2 & 1 & 7 & 0 \\
\hline Landa et al, 2020 & 3 & 0 & 0 & 0 & 3 & 0 \\
\hline $\begin{array}{l}\text { Alramthan and Al- } \\
\text { daraji, } 2020\end{array}$ & 2 & 0 & 0 & 0 & 2 & 0 \\
\hline Marzano et al, 2020 & 22 & 0 & 22 & 0 & 0 & 22 \\
\hline Diotallevi et al, 2020 & 3 & 2 & 0 & 2 & 0 & 0 \\
\hline De Giorgi et al, 2020 & 53 & 37 & 2 & 14 & 13 & 0 \\
\hline Total & 151 & 76 & 33 & 23 & 29 & 25 \\
\hline
\end{tabular}




\section{Results}

We identified 14 articles which fulfill our inclusion criteria detailed in Table 1, 12 of which showed comparable results and included in pooled analysis while 2 more were less comparable and analyzed separately. Most included articles described cases in Italy, with two studies in United States, and one study each describing cases in Russia, India, France, and Spain. Many of these articles does not describe exclusively confirmed SARS-CoV-2 infected patients, some also described suspected cases or cases with negative result for RT-PCR test for SARS-CoV-2. Some studies also described clinical manifestation in general, with dermatological manifestation being one subset of clinical manifestations described.

Few articles described the frequency of dermatological manifestation among general SARS-CoV-2 infected population. Recalcati et al [4] was one that describe that among 88 patients with confirmed SARS-CoV-2 infection, 18 (20.4\%) showed cutaneous manifestation. Similarly, De Giorgi et al [15] described that among 678 patients with confirmed SARS-CoV-2 infection, 53(7.8\%) with inflammatory cutaneous manifestations and $13(1.9 \%)$ with vascular cutaneous manifestations.

\section{Types of Cutaneous Efflorescence}

We included 151 confirmed SARS-CoV-2 infection cases in our pooled analysis as can be seen in Table 2. The most frequent form of cutaneous efflorescence found in COVID-19 patients was erythematous maculopapular rash or morbilliform rash which was found $76(50.3 \%$ ) patients. Other forms of cutaneous efflorescence found among confirmed SARS-CoV-2 infected patients included vesicle, pustule, or bullae which was found in 33(21.9\%) patients, urticaria, papulosquamous eruptions found in $25(16.6 \%)$, and urticaria found in $23(15.2 \%)$ patients.

Our pooled analysis found a number of vascular eruptions, including petechiae, purpura, vasculitis, and chilblain/pernio, which was found in 29(19.2\%) patients. Apart from the pooled analyses, Freeman et al [17] found 46 cases of confirmed SARS-CoV-2 patients, out of 171 described in the study, with vascular various. Another 23 cases of confirmed SARS-CoV-2 infection with pernio/chilblain was found by Freeman et al [16].

As can be noted from Table 2, the numbers do not add up to one hundred percent. This is due to the possibility that each case suffered more than one type of eruptions. This phenomenon is noted by Freeman et al which described that among 171 confirmed SARS-CoV-2 infections that exhibited cutaneous eruptions, 6 suffered multiple eruptions [17].

\section{Localization}

The most frequent localization for cutaneous efflorescence of SARS-CoV-2 infection was the trunk of the body. Ten out of twelve comparable studies provided data on lesion localizations with a total of 66 cases, as can be seen in Table 3. From these cases, $45(68.2 \%)$ was found with lesions localized to the trunk of the body. Extremities, including arms and legs, was found in

Table 3. Localizations of cutaneous eruptions in COVID-19 patients.

\begin{tabular}{|c|c|c|c|c|c|}
\hline Reference & $\begin{array}{c}\text { Number of } \\
\text { Cases }\end{array}$ & Trunk & $\begin{array}{c}\text { Extremities } \\
\text { (Arms/Legs) }\end{array}$ & Hands/Feet & Generalized \\
\hline Sachdeva et al, 2020 & 3 & 3 & 0 & 0 & 0 \\
\hline Gianotti et al, 2020 & 3 & 3 & 1 & 0 & 0 \\
\hline Dalal et al, 2020 & 13 & 9 & 2 & 0 & 3 \\
\hline Potekaev et al, 2020 & 15 & 6 & 8 & 3 & 1 \\
\hline Tammaro et al, 2020 & 2 & 2 & 0 & 0 & 0 \\
\hline Landa et al, 2020 & 3 & 0 & 3 & 0 & 0 \\
\hline Alramthan and Aldaraji, & 2 & 0 & 2 & 0 & 0 \\
\hline 2020 & 22 & 22 & 4 & 0 & 0 \\
\hline Marzano et al, 2020 & 3 & 0 & 1 & 1 & 2 \\
\hline Diotallevi et al, 2020 & 66 & 45 & 21 & 4 & 6 \\
\hline Total & & & & & \\
\hline
\end{tabular}

Table 4. Distribution of onset and associated symptoms of cutaneous manifestations of COVID-19.

\begin{tabular}{|c|c|c|c|}
\hline \multirow{2}{*}{ Reference } & Number of Cases & \multicolumn{2}{c|}{ Associated Symptoms } \\
\cline { 2 - 4 } & (Associated Symptoms) & Pruritus & Pain/Burning \\
\hline Sachdeva et al, 2020 & 3 & 1 & 2 \\
\hline Recalcati et al, 2020 & 18 & 8 & 10 \\
\hline Dalal et al, 2020 & 13 & 10 & 3 \\
\hline Potekaev et al, 2020 & 15 & 8 & 7 \\
\hline Marzano et al, 2020 & 22 & 22 & 0 \\
\hline De Giorgi et al, 2020 & 53 & 23 & 30 \\
\hline Total & 124 & 72 & 52 \\
\hline
\end{tabular}


Table 5. Summary of cutaneous eruptions of COVID-19.

\begin{tabular}{|c|c|}
\hline \multirow{4}{*}{ Maculopapular rash } & Morbilliform rash \\
\cline { 2 - 2 } & Papulosquamous rash \\
\cline { 2 - 2 } & Plaque \\
\cline { 2 - 2 } Vesicular rash & Pityriasis rosea-like rash \\
\hline \multirow{3}{*}{ Urticaria } & Urticaria \\
\cline { 2 - 2 } & Varicella-like rash \\
\hline \multirow{4}{*}{ Vascular rash } & Pullae \\
\cline { 2 - 2 } & Petechiae \\
\cline { 2 - 2 } & Purpura \\
\cline { 2 - 2 } & Vasculitis \\
\cline { 2 - 2 } & Chilblain-like rash \\
\hline
\end{tabular}

$21(31.8 \%)$ of cases while lesion on hands, feet, and fingers/toes, was found in $4(6.1 \%)$ of cases. Meanwhile $6(9.1 \%)$ of cases experienced generalized lesions.

Freeman et al described a more detailed localizations of cutaneous lesions from 171 confirmed SARS-CoV-2 cases [17]. Broken down based on types of efflorescence, most lesions were predominantly found on the trunk. Lesions were found on chest, abdomen, and back of, respectively, $50 \%, 63 \%$, and $61 \%$ of cases with maculopapular morbilliform lesions. Similar distribution, albeit lower, was found for urticaria and vesicular lesions. Meanwhile, chilblain lesions were found predominantly on the feet, with $84 \%$ of cases, rather than hands, with only $32 \%$ of cases.

In a marked difference from our pooled analyses, Freeman et al described significant amount of eruption localized on the head and face region [17]. Face is the more predominant localization among the two with $21 \%$ of maculopapular rashes, $30 \%$ of urticaria, and $33 \%$ of vesicular rashes found on faces of the patients. Our pooled analyses found no description of cutaneous eruptions on the head and face region.

\section{Associated Symptoms}

Six of the included studies described associated cutaneous symptoms associated with the eruption, including pruritus and pain. From these studies, we included 124 cases in pooled analysis, as visible in Table 4 , and identified that $72(58.1 \%)$ of cases complained of pruritus while another $52(41.9 \%$ ) cases complained of pain or burning sensation of the lesion. Note that our pooled analysis does not describe the intensity of the symptoms which may vary. Marzano et al, for example, described his 22 cases with which suffered varicella-like vesicles to suffer mild pruritus [13].

Freeman et al, mean while, varying associated symptoms based on type of eruptions suffered by the patients [17]. Pruritus was the predominant symptoms among patients which suffered morbilliform maculopapular rash and urticaria with $61 \%$ and $74 \%$ of cases respectively, while cases with chilblain mainly complained of pain or burning sensation with $71 \%$ of the cases. Patients with vesicular eruption, mean while, suffered both pruritus and pain with $72 \%$ suffered pruritus and $50 \%$ suffered pain or burning sensation.

\section{Discussion}

There has been little to no systematic population-based research to study cutaneous eruption on SARS-CoV-2 infected patients. Most available literatures were case reports or case studies with varying number of reported cases and description detail. Some studies reporting dermatologic features of SARS-CoV-2 infections also included suspected cases or cases with negative SARSCoV-2 RT-PCR results, meanwhile others failed to conduct diagnostic tests to exclude other infectious causes for the described cutaneous eruptions. With this situation, there has been no established studies to definitively linked these eruptions to be caused by SARS-CoV-2 infection although some pathophysiologic mechanisms have been proposed. Nevertheless, our literature review has identified two major themes of discussions, namely the description of the major cutaneous manifestations of COVID-19 as well as its pathophysiologic mechanisms.

\section{Describing Types Of Eruption Associated With COVID-19}

Our review of literature identified several types of cutaneous eruption that has been thematically described to be associated with SARS-CoV-2 infection or COVID-19 which is summarized in Table 5. These includes maculopapular/morbilliform rash, varicella-like vesicular rash, and vasculitis or vascular rash.

Maculopapular or morbilliform rash with distribution predominantly on the trunk and upper extremities was found to be the dominant form of cutaneous eruption found in COVID-19 patients, based on our pooled analyses. This is also compounded by similarly described papulosquamous eruptions, which may share similar process of formation with aforementioned maculopapular rash.

Prevalence of similarly described rash has been previously described in reviews by Suchonwanit et al [18] and Wollina et al [19]. Wollina et al further described the maculopapular rash in a spectrum from morbilliform rash to papulosquamous plaques or pityriasis rosea-like lesion, accompanied by pruritus [19]. This is similar to our findings.

Vesicular eruption, including bullae and pustule, was also frequently found among COVID-19 patients. Marzano et al de- 
Figure 1. Summary of proposed pathophysiology of SARS-CoV-2 infection and its associated cutaneous eruptions.

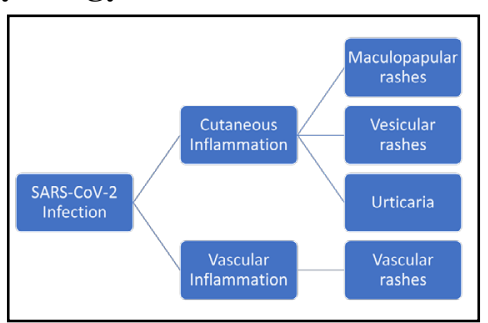

scribed a cohort of 22 patients who all exhibited vesicopapular exanthema with age mostly in the adult to elderly range, with one exception of a 8-year old child [13]. Wollina et al has noted that chickenpox-like vesicular eruption was found in $1 \%$ to $9 \%$ of confirmed SARS-CoV-2 infections [19].

Mean while, vascular eruptions among COVID-19 patients varied from petechiae and purpura to chilblain. Chilblain is particularly described among COVID-19 patients with a recent Spanish study reporting $19 \%$ of confirmed SARS-CoV-2 infection [20]. Chilblain is a lesion of particular interests with several studies focusing on describing chilblain-like lesions among children suspected of COVID-19 [21-23]. However, these studies included both suspected cases and confirmed SARS-CoV-2 negative patients in their description, making it difficult to establish association of these lesions with exclusive SARS-CoV-2 infection as its etiology.

\section{Pathophysiology Of Cutaneous Eruptions In COVID-19}

There are two pathologic mechanism suspected to play a role in cutaneous manifestations of COVID-19, each with differing types of cutaneous eruptions. The proposed mechanisms and its pathways to cutaneous eruptions can be seen in Figure 1.

The first suspected mechanism is an antibody mediated immune response against a pathogenic virus. It is suspected that cutaneous eruptions, especially inflammatory eruptions such as exanthems and vesicular rashes, to be caused by antibody-antigen reaction in or near dermatologic tissues [24]. It has been further demonstrated that SARS-CoV-2 entry factor, ACE2, was found to be expressed in skin tissue as well, mainly in keratinocytes and basal layer, probably contributing to local inflammation in those tissue in event of SARS-CoV-2 infection [25].

Mean while, this immune system and antibody mediated pathophysiology is found to be less likely mechanism for vascular eruptions of COVID-19, such as petechiae, purpura, and chilblain-like lesions. This premise was proposed by Mahieu et al who found no anti-SARS-CoV-2 antibodies on these lesions [26]. As such, the second proposed mechanism come into play, which involved thrombosis and endothelial damage related to SARS-CoV-2 infection.

SARS-CoV-2 infection has been previously associated with hypercoagulable state, as evident by increasing risk of thromboembolism [27]. This hypercoagulable state, as well as formation of thromboembolism, may be associated with expression of ACE2 in endothelial tissues, mediating viral invasion of these tissues, causing damage through inflammation and viral activities [28].

This hypercoagulable state and thromboembolism are proposed to be associated with the process that manifested as vascular lesion on the skin. Vascular damages on superficial blood vessels near skin surfaces may be visible as vasculitis, petechiae, or purpura. Meanwhile, vascular blockage due to thromboembolism may be associated with chilblain-like lesions associated with COVID-19.

\section{Acknowledgements}

We reviewed data and materials available the current time, it may be limited compared to future literature which would have shed more light on the association between SARS-CoV-2 infections and cutaneous eruptions. Nevertheless, we identified several groups of cutaneous eruptions associated with COVID-19, namely maculopapular rash, urticaria, vesicular rash, and vascular rash. These different eruptions were proposed to be caused SARS-CoV-2 infection with different pathophysiological mechanisms, namely inflammation and hypercoagulable state. Inflammation near skin surfaces was associated with maculopapular rashes, urticaria, and vesicles while hypercoagulation of superficial blood vessels may manifest as petechiae, purpura, vasculitis, or chilblain. More studies needs to be conducted to definitively associate these various cutaneous eruptions with SARS-CoV-2.

\section{References}

[1]. World Health Organization. WHO Coronavirus Disease (COVID-19) Dashboard.[online] covid19. who. int.

[2]. Azfar NA, Zaman T, Rashid T, Jahangir M. Cutaneous manifestations in patients of hepatitis C. Journal of Pakistan Association of Dermatologists. 2008;18(3):138-43.

[3]. Gulati A, Pomeranz C, Qamar Z, Thomas S, Frisch D, George G, et al. A Comprehensive Review of Manifestations of Novel Coronaviruses in the Context of Deadly COVID-19 Global Pandemic. Am J Med Sci. 2020 Jul;360(1):5-34. Pubmed PMID: 32620220.

[4]. Recalcati S. Cutaneous manifestations in COVID-19: a first perspective. J Eur Acad Dermatol Venereol. 2020 May;34(5):e212-e213. Pubmed PMID: 32215952.

[5]. Sachdeva M, Gianotti R, Shah M, Bradanini L, Tosi D, Veraldi S, et al. Cutaneous manifestations of COVID-19: Report of three cases and a review of literature. J Dermatol Sci. 2020 May;98(2):75-81. Pubmed PMID: 32381430 .

[6]. Gianotti R, Zerbi P, Dodiuk-Gad RP. Clinical and histopathological study of skin dermatoses in patients affected by COVID-19 infection in the Northern part of Italy. J Dermatol Sci. 2020 May;98(2):141-143. Pubmed PMID: 32381428.

[7]. Dalal A, Jakhar D, Agarwal V, Beniwal R. Dermatological findings in SARSCoV-2 positive patients: An observational study from North India. Dermatol Ther. 2020 Nov;33(6):e13849. Pubmed PMID: 32543757.

[8]. Potekaev NN, Zhukova OV, Protsenko DN, Demina OM, Khlystova EA, Bogin V. Clinical characteristics of dermatologic manifestations of COVID-19 infection: case series of 15 patients, review of literature, and proposed etiological classification. Int J Dermatol. 2020 Aug;59(8):1000-1009. Pubmed PMID: 32621287.

[9]. Tammaro A, Adebanjo GAR, Parisella FR, Pezzuto A, Rello J. Cutaneous manifestations in COVID-19: the experiences of Barcelona and Rome. J Eur Acad Dermatol Venereol. 2020 Jul;34(7):e306-e307. Pubmed PMID: 32330340.

[10]. Bouaziz JD, Duong TA, Jachiet M, Velter C, Lestang P, Cassius C, et al. Vascular skin symptoms in COVID-19: a French observational study. J 
Eur Acad Dermatol Venereol. 2020 Sep;34(9):e451-e452. Pubmed PMID: 32339344

[11]. Landa N, Mendieta-Eckert M, Fonda-Pascual P, Aguirre T. Chilblain-like lesions on feet and hands during the COVID-19 Pandemic. Int J Dermatol. 2020 Jun;59(6):739-743. Pubmed PMID: 32329897.

[12]. Alramthan A, Aldaraji W. Two cases of COVID-19 presenting with a clinical picture resembling chilblains: first report from the Middle East. Clin Exp Dermatol. 2020 Aug;45(6):746-748. Pubmed PMID: 32302422.

[13]. Marzano AV, Genovese G, Fabbrocini G, Pigatto P, Monfrecola G, Piraccini BM, et al. Varicella-like exanthem as a specific COVID-19-associated skin manifestation: Multicenter case series of 22 patients. J Am Acad Dermatol. 2020 Jul;83(1):280-285. Pubmed PMID: 32305439.

[14]. Diotallevi F, Campanati A, Bianchelli T, Bobyr I, Luchetti MM, Marconi B, et al. Skin involvement in SARS-CoV-2 infection: Case series. J Med Virol. 2020 Nov;92(11):2332-2334. Pubmed PMID: 32410241.

[15]. De Giorgi V, Recalcati S, Jia Z, Chong W, Ding R, Deng Y, et al. Cutaneous manifestations related to coronavirus disease 2019 (COVID-19): A prospective study from China and Italy. J Am Acad Dermatol. 2020 Aug;83(2):674675. Pubmed PMID: 32442696.

[16]. Freeman EE, McMahon DE, Lipoff JB, Rosenbach M, Kovarik C, Takeshita J, et al. Pernio-like skin lesions associated with COVID-19: A case series of 318 patients from 8 countries. J Am Acad Dermatol. 2020 Aug;83(2):486492. Pubmed PMID: 32479979.

[17]. Freeman EE, McMahon DE, Lipoff JB, Rosenbach M, Kovarik C, Desai SR, et al. The spectrum of COVID-19-associated dermatologic manifestations: An international registry of 716 patients from 31 countries. J Am Acad Dermatol. 2020 Oct;83(4):1118-1129. Pubmed PMID: 32622888.

[18]. Suchonwanit P, Leerunyakul K, Kositkuljorn C. Cutaneous manifestations in COVID-19: Lessons learned from current evidence. J Am Acad Dermatol. 2020 Jul;83(1):e57-e60. Pubmed PMID: 32339706.

[19]. Wollina U, Karadağ AS, Rowland-Payne C, Chiriac A, Lotti T. Cutaneous signs in COVID-19 patients: A review. Dermatol Ther. 2020 Sep;33(5):e13549. Pubmed PMID: 32390279.

[20]. Galván Casas C, Català A, Carretero Hernández G, Rodríguez-Jiménez P,
Fernández-Nieto D, Rodríguez-Villa Lario A, et al. Classification of the cutaneous manifestations of COVID-19: a rapid prospective nationwide consensus study in Spain with 375 cases. Br J Dermatol. 2020 Jul;183(1):71-77. Pubmed PMID: 32348545.

[21]. Roca-Ginés J, Torres-Navarro I, Sánchez-Arráez J, Abril-Pérez C, SabalzaBaztán O, Pardo-Granell S, et al. Assessment of Acute Acral Lesions in a Case Series of Children and Adolescents During the COVID-19 Pandemic. JAMA Dermatol. 2020 Sep 1;156(9):992-997. Pubmed PMID: 32584397.

[22]. de Masson A, Bouaziz JD, Sulimovic L, Cassius C, Jachiet M, Ionescu MA, et al. Chilblains is a common cutaneous finding during the COVID-19 pandemic: A retrospective nationwide study from France. J Am Acad Dermatol. 2020 Aug;83(2):667-670. Pubmed PMID: 32380219.

[23]. Piccolo V, Neri I, Filippeschi C, Oranges T, Argenziano G, Battarra VC, et al A. Chilblain-like lesions during COVID-19 epidemic: a preliminary study on 63 patients. J Eur Acad Dermatol Venereol. 2020 Jul;34(7):e291-e293. Pubmed PMID: 32330334.

[24]. Gupta S, Gupta N, Gupta N. Classification and pathophysiology of cutaneus manifestations of COVID-19. Int J Res Dermatol. 2020 Jul;6(4):1-5.

[25]. Zhao Q, Fang X, Pang Z, Zhang B, Liu H, Zhang F. COVID-19 and cutaneous manifestations: a systematic review. J Eur Acad Dermatol Venereol. 2020 Nov;34(11):2505-2510. Pubmed PMID: 32594572.

[26]. Mahieu R, Tillard L, Le Guillou-Guillemette H, Vinatier E, Jeannin P, Croué A, et al. No antibody response in acral cutaneous manifestations associated with COVID-19? J Eur Acad Dermatol Venereol. 2020 Oct;34(10):e546e548. Pubmed PMID: 32488946.

[27]. Chen J, Wang X, Zhang S, Liu B, Wu X, Wang Y, et al. Findings of acute pulmonary embolism in COVID-19 patients. Available at SSRN 3548771. 2020 Mar 1.

[28]. Varga Z, Flammer AJ, Steiger P, Haberecker M, Andermatt R, Zinkernagel AS, et al. Endothelial cell infection and endotheliitis in COVID-19. Lancet. 2020 May 2;395(10234):1417-1418. Pubmed PMID: 32325026. 